\title{
Antioxidant potential of melatonin enhances the response to L-dopa in 1-methyl 4-phenyl 1,2,3,6-tetrahydropyridine-parkinsonian mice
}

\author{
Sawsan A. Zaitone ${ }^{1}$, Lamiaa N. Hammad², Noha E. Farag ${ }^{3}$ \\ ${ }^{1}$ Department of Pharmacology and Toxicology, Faculty of Pharmacy, Suez Canal University, Ismailia 41522, Egypt \\ ${ }^{2}$ Department of Biochemistry, Faculty of Pharmacy, Misr International University, Cairo, Egypt \\ ${ }^{3}$ Department of Physiology, Faculty of Medicine, Suez Canal University, Ismailia 41522, Egypt
}

Correspondence: Sawsan A. Zaitone, e-mail: Sawsan_zaytoon@pharm.suez.edu.eg

\begin{abstract}
:
Background: Parkinson's disease is a neurodegenerative disorder of uncertain pathogenesis characterized by a loss of dopaminergic neurons in substantia nigra pars compacta, and can be modeled by the neurotoxicant 1-methyl-4-phenyl-1,2,3,6-tetrahydropyridine (MPTP). The current research was directed to investigate the role of melatonin in preventing the gradual decrease in the response to L-dopa in MPTP-induced parkinsonism in mice.

Methods: Eighty four male Swiss mice were divided into seven groups. Group I is the saline group. The other six groups were injected with MPTP $(20 \mathrm{mg} / \mathrm{kg} / 2 \mathrm{~h})$. Group II is the MPTP control group. Group III was treated with L-dopa/carbidopa (100/10 mg/kg, po). Group IV and V were treated with melatonin ( 5 or $10 \mathrm{mg} / \mathrm{kg}$, po), respectively. Group VI and VII received L-dopa/carbidopa in combination with melatonin in the same above-mentioned doses, respectively.

Results: Results showed that MPTP-treated mice exhibited low striatal dopamine level accompanied by motor impairment and increased oxidative stress. Treatment with L-dopa improved the motor performance of mice. Addition of melatonin to L-dopa therapy improved the motor response to L-dopa and increased striatal dopamine level. This combination reduced lipid peroxidation, ameliorated reduced glutathione and improved antioxidant enzyme activities $(\mathrm{p} \leq 0.05)$.

Conclusions: Overall, our study suggests that the antioxidant potential of melatonin makes it a promising candidate to L-dopa in treating Parkinson's disease.
\end{abstract}

Key words: L-dopa, melatonin, mice, MPTP, oxidative stress, Parkinson’s disease, wearing off

\begin{abstract}
Abbreviations: CAT - catalase, GP-x - glutathione peroxidase, $\mathrm{GSH}$ - reduced glutathione, $\mathrm{H}_{2} \mathrm{O}_{2}$ - hydrogen peroxide, MDA - malondialdehyde, MPTP - 1-methyl-4-phenyl-1,2,3,6tetrahydropyridine, PBS - phosphate-buffered saline, $p o$ - per os, PD - Parkinson's diseases, SNpc - substantia nigra pars compacta, SOD - superoxide dismutase, TH - tyrosine hydroxylase
\end{abstract}

\section{Introduction}

Parkinson's disease (PD) is a progressive neurological disorder characterized by the loss of dopamine in the striatum; which occurs mainly due to the death of the 
dopaminergic neurons in the substantia nigra pars compacta (SNpc). The concept of oxidative stress and antioxidants may be directly or indirectly involved in the pathogenesis of $\mathrm{PD}$ [32] and in animal models [57]. MPTP is a potent and selective nigrostriatal dopaminergic neurotoxicant that can induce parkinsonism when administered to rodents [39], showing evidence of oxidative stress in these models [13, 48].

The currently available pharmacological and nonpharmacological treatments for PD are able to offer only symptomatic relief for patients. Since its introduction in the late $1960 \mathrm{~s}$, L-dopa (L-3,4-dihydroxyphenylalanine) has been the cornerstone of the treatment of PD. However, the effectiveness of L-dopa therapy declines on continuous use [7]. Another potential problem with the use of L-dopa in treatment of PD comes from the fact that L-dopa metabolism or autoxidation can give rise to radical species, hydrogen peroxide $\left(\mathrm{H}_{2} \mathrm{O}_{2}\right)$, semiquinones, and quinones [17]. The quinones generated are thought to mediate toxicity by covalent binding to nucleophilic groups of biological macromolecules [47]. L-dopa has been shown to induce oxidative stress-mediated apoptosis in cultured neuronal cells [56]. However, there is no evidence from in vivo studies suggesting that L-dopa treatment damages SNpc neurons in PD. Medical therapy that keeps the benefits of L-dopa would be a major advance in the treatment of PD [36]. Recently, it has been postulated that during the preclinical phase of PD the turnover rate of dopamine may increase to compensate the loss of dopamine containing neurons [14]. This increase in the rate of dopamine utilization is likely to accelerate the neurodegenerative process through the generation of quinones, semiquinones and $\mathrm{H}_{2} \mathrm{O}_{2}$, resulting from the oxidative metabolism of dopamine [17].

Melatonin, a serotonin derivative is a hormone synthesized by neurons in the pineal gland. Studies have demonstrated that melatonin has antioxidant properties by acting as a free radical scavenger [52]. Melatonin has been also associated with the cellular antioxidant defense. It can develop its action at two levels: as a direct antioxidant, due its ability to act as a free radical scavenger, and as an indirect antioxidant, since it is able to induce the expression and/or the activity of the main antioxidant enzymes [54]. It has been shown to cause a considerable dose-dependent reduction in the production of dopaminergic neurodegenerating hydroxyl free radicals [2]. In addition, melatonin is also indirectly effective by enhancing the levels of potential antioxidants such as glutathione peroxi- dase (GSH-Px), superoxide dismutase (SOD) and reduced glutathione (GSH) [19].

Using the hypothesis that oxidative injury underlies the reduction in response to L-dopa, the inclusion of antioxidants with L-dopa treatment may retard the decline in response to L-dopa after long term use. The present study was designed to characterize the effect of melatonin in improving the longevity of L-dopa treatment in the MPTP mouse model of PD.

\section{Materials and Methods}

\section{Animals}

Eighty four male Swiss albino mice were used in the present study. Their weight ranged between 20-25 g. Mice were housed in groups of four in stainless steel cages under hygienic controlled laboratory conditions (reversed light/dark cycle, temperature $25 \pm 3{ }^{\circ} \mathrm{C}$ and $55 \%$ relative humidity) and acclimatized for 7 days prior to start of the experiment. Water and food pellets were provided ad libitum. Behavioral tests were performed daily from 4 to 6 p.m. to minimize circadian influence on the mice behavior. The experimental protocol was approved by the Institutional Animal Care and Use Committee at the Faculty of Pharmacy, Suez Canal University.

\section{Chemicals and drugs}

1-Methyl-4-phenyl-1,2,3,6-tetrahydropyridine $\mathrm{HCl}$ (Sigma-Aldrich, St. Louis, MO, USA) powder was dissolved in sterile saline. Melatonin powder was purchased from Bio Basic Inc. (Ontario, Canada) and dissolved in $2 \%$ Tween- 80 solution. L-dopa and carbidopa were kindly provided by Global Napi Pharmaceuticals (Cairo, Egypt) and dissolved in distilled water.

\section{Experimental design}

Mice were randomly divided into seven groups; twelve mice each. Group I: was injected with saline ( $3 \mathrm{ml} / \mathrm{kg} / 2 \mathrm{~h}$, ip). The other six groups received 4 intraperitoneal injections of MPTP $(20 \mathrm{mg} / \mathrm{kg} / 2 \mathrm{~h})$. Group II: MPTP group, served as a control group. Group III: mice received L-dopa/carbidopa (100/10 mg/ $\mathrm{kg} /$ twice/day, $p o$ ). Group IV: mice received melatonin $(5 \mathrm{mg} / \mathrm{kg} /$ day, po). Group V: mice received melatonin 


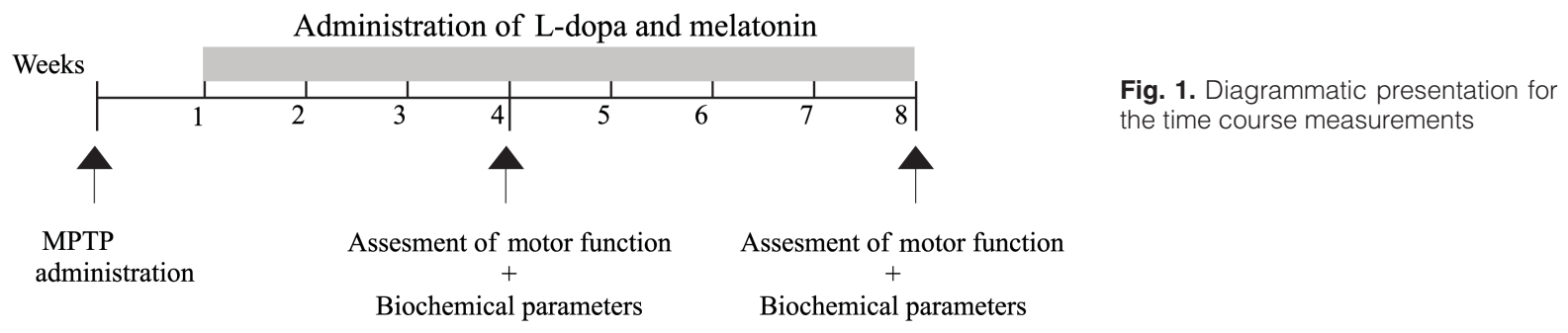

$(10 \mathrm{mg} / \mathrm{kg} /$ day, $p o)$. Group VI and VII: mice received L-dopa/carbidopa as well as melatonin in the same aforementioned doses, respectively. Treatment with L-dopa/carbidopa or melatonin was initiated at day 8 in a volume of $5 \mathrm{ml} / \mathrm{kg}$. MPTP group received a similar volume of the drug vehicles parallel to drug treatments. At the end of week 4, five randomly selected mice from each group were tested for their locomotor activity and then, sacrificed. The remaining mice were maintained until the end of week 8 and sacrificed at this time point (Fig. 1). MPTP manipulations were carried out in a special animal room restricted for the neurotoxicant.

\section{Assessment of mortality percentage}

As Swiss mice are not often used in MPTP model (mostly used are C57BL/6 mice), the mortality percentage was calculated (out of 12) for each group at the end of week 4 and week 8 . In addition, functional assessment was performed for the selected mice at the same time points to ensure the sensitivity of Swiss mice to MPTP.

\section{Functional assessment}

Mice were screened for motor impairment using a battery of behavioral tests. The tests were the grid walking test, open field test and rotarod test. On the testing day, mice were screened for their motor function 30 min after drug (or vehicle) treatments (the expected "on" time for L-dopa treatment) and compared to the MPTP control group.

\section{Grid walking test}

The grid test assesses the ability to accurately place the forepaws during spontaneous exploration of an elevated grid by analyzing the frequency with which the mice failed to accurately grasp the rungs. Mice were placed on a wire circular grid $(330 \mathrm{~mm}$ in di- ameter with $15 \times 15 \mathrm{~mm}$ grid squares) and allowed to freely explore for $3 \mathrm{~min}$. Mice were videotaped and at a later date an experimenter blinded to the treatment group scored the percentage of foot slips out of the first 50 steps taken with the left and right fore and hind paws. A foot slip was scored either when the paw completely missed a rung and thus the limb fell between the rungs and the animal lost balance, or when the paw was correctly placed on the rung but slipped off during weight bearing [31]. The animals required no pretraining but were placed on the grid twice prior to MPTP injection for habituation. Mice were then tested at the end of the experiment.

\section{Open-field test}

The open-field arena, had the measurements $113 \times$ $113 \times 44 \mathrm{~cm}$, the floor of the arena was painted with white lines to form a $5 \times 5 \mathrm{~cm}$ pattern [10]. Mice were naive to the open field arena and introduced individually to it where the locomotor behavior was videorecorded for $5 \mathrm{~min}$. The film was later observed by a trained blind observer. Ambulation (number of squares crossed) in a 5-min session was registered for each mouse.

\section{Fixed speed rotarod test}

The experiment was conducted using a rotor with a 4-cm diameter and rotating at a constant speed (6 rpm). Before starting the experiment, mice were given a training session for 3 consecutive days (before administration of MPTP). Mice that were able to stay on the rotarod for at least one min were included in the study and randomly divided into the different experimental groups. At the testing day, falling time (time starting from putting the animal on the rotarod, till it falls to the ground) was measured in seconds. Each mouse was tested three times and the mean of these three trials was used for comparison. The cut-off time was set as $180 \mathrm{~s}$. 


\section{Processing of the brains}

After assessment of the motor performance, mice were anesthetized using thiopental sodium $(50 \mathrm{mg} / \mathrm{kg})$ and sacrificed by cervical decapitation. After that, the brains were quickly dissected and washed with ice cold phosphate-buffered saline (PBS) and one hemisphere from each brain was rapidly frozen at $-80^{\circ} \mathrm{C}$. Then, the striata were isolated and used for extraction of dopamine. The substantia nigra from these brains were isolated for determination of the oxidative stress parameters as described later.

The second hemisphere of all brains were fixed using $4 \%$ paraformaldehyde in $0.1 \mathrm{M}$ phosphate buffer, $\mathrm{pH}=7.2$ overnight and then embedded with paraffin. All paraffin-embedded tissues were sectioned at $4 \mu \mathrm{m}$, deparaffinized in xylene, and hydrated by ethyl alcohol in decreasing concentrations $(100,95$ and $70 \%$ ). Further, these sections were processed to immunohistochemical staining for tyrosine hydroxylase (TH) or caspase- 3 enzyme.

\section{Biochemical analyses in the brain homogenate}

\section{Determination of striatal dopamine level}

The striatal dopamine level was determined using an HPLC apparatus with an electrochemical detector (Model 5600A CoulArray Detector System ESA, Brighton, MA, USA). Briefly, tissues were homogenized in $0.2 \mathrm{M}$ ice-cold perchloric acid. The homogenate was placed in an ice bath for $60 \mathrm{~min}$. Subsequently, the sample was centrifuged at $15,000 \times g$ for $20 \mathrm{~min}$ at $4^{\circ} \mathrm{C}$ and the supernatant was transferred to a clean tube and measured for volume. One-half volume of a solution containing $0.02 \mathrm{M}$ potassium citrate, $0.3 \mathrm{M}$ potassium dihydrogen phosphate, and $0.002 \mathrm{M} \mathrm{Na}_{2}$ EDTA was added and mixed thoroughly to deposit perchloric acid. After incubation in an ice bath for $60 \mathrm{~min}$, the mix was centrifuged at $15,000 \times$ $g$, for $20 \mathrm{~min}$ at $4^{\circ} \mathrm{C}$. The supernatant was filtered through a $0.22 \mu \mathrm{m}$ Millipore filter and then injected into the HPLC system for analysis. The mobile phase was $0.125 \mathrm{M}$ sodium citrate buffer containing $20 \%$ methanol, $0.1 \mathrm{mM} \mathrm{Na} 2$ EDTA, $0.5 \mathrm{mM}$ 1-octanesulfonic acid sodium salt (Acros Organics, Morris Plains, NJ, USA.) adjusted to $\mathrm{pH}=4.3$. The flow rate was set at $1.2 \mathrm{ml} / \mathrm{min}$. Dopamine level was expressed in $\mu \mathrm{M} / \mathrm{g}$ tissue.
Determination of tissue MDA, GSH, GSH-Px, SOD and CAT

The substantia nigra from each brain was removed, blotted and weighed, and then homogenized in Tris buffer (10 mM Tris $\mathrm{HCl}, 1 \mathrm{mM}$ EDTA, $0.32 \mathrm{M}$ sucrose, $\mathrm{pH}=7.8)$ as $10 \%(\mathrm{w} / \mathrm{v})$ using a teflon homogenizer (Glas Col homogenizer system, Vernon Hills, USA). The homogenate was sonicated and centrifuged at $20,000 \times g$ for $10 \mathrm{~min}$, then, supernatant was kept at $-80^{\circ} \mathrm{C}$ until determination of malondialdehyde (MDA), GSH, glutathione peroxidase (GSH-Px), SOD and catalase (CAT) by spectrophotometric methods. Tissue MDA was determined using a spectrophotometric method depending on the reaction with thiobarbituric acid; using 1,1,3,3-tetramethoxypropane as a standard [35]. Determination of the concentration of total glutathione (GSH and GSSG) and oxidized glutathione (GSSG) was done spectrophotometrically using commercial kits according to the instructions of the manufacturer $[18,53]$. Total GSH content was expressed in $\mu \mathrm{M} / \mathrm{g}$ protein.

Estimation of GSH-Px was done following the indirect method of Paglia and Valentine [37]. The method depends on the fact that GSSG produced upon reduction of an organic peroxide by GSH-Px is recycled to its reduced state by the enzyme glutathione reductase. The oxidation of NADPH to NADP ${ }^{+}$is accompanied by a decrease in absorbance at $340 \mathrm{~nm}$ [37]. SOD activity was estimated using the method of Nishikimi et al. [34]. This assay relies on the ability of the enzyme to inhibit the phenazine methosulfatemediated reduction of nitroblue tetrazolium dye [34]. CAT activity was assessed as reported by Aebi [4]; the assay depends on that CAT reacts with a known quantity of $\mathrm{H}_{2} \mathrm{O}_{2}$ and the remaining amount of $\mathrm{H}_{2} \mathrm{O}_{2}$ reacts with 3,5-dichloro-2-hydroxybenzene sulfonic acid (DHBS) and 4-aminophenazone to form a chromophore with a color intensity inversely proportional to the amount of CAT in the original sample [4]. Protein content was determined following the colorimetric method of Lowry et al. [27] and all samples were normalized for protein content. The values of absorbance were measured using a UV-visible spectrophotometer (UV-1601PC, Shimadzu, Japan).

\section{Immunohistochemistry and image analysis}

For immunohistochemical staining, sections were fixed in an oven at $65^{\circ} \mathrm{C}$ for $1 \mathrm{~h}$ and then the slides were 
placed in a coplin jar filled with $60 \mathrm{ml}$ of triology (Cell Marque ${ }^{\circledR}$, CA, USA) working solution and the jar was securely positioned in an autoclave. The autoclave was adjusted at $120^{\circ} \mathrm{C}$ and maintained for $15 \mathrm{~min}$ and the coplin jar was removed and slides were allowed to cool for $30 \mathrm{~min}$. Sections were then washed and immersed in TBS to adjust the $\mathrm{pH}$, this is repeated between each step of the immunohistochemical procedure. Without washing, excess serum was drained from each slide and 2-3 drops of rabbit monoclonal tyrosine hydroxylase primary antibodies $(1: 100, \mathrm{R} \& \mathrm{D}$ systems ${ }^{\circledR}$, Minneapolis, USA) or ready to use rabbit polyclonal caspase-3 antibodies (Thermoscientific ${ }^{\circledR}$, Fremont, CA, USA). Then, slides were incubated in the humidity chamber for $1 \mathrm{~h}$. After that, biotinylated secondary antibody was applied on each slide for $20 \mathrm{~min}$ and then incubated with the enzyme conjugate for 20 min. DAB chromogen was prepared and 2-3 drops were applied on each slide for $2 \mathrm{~min}$. Henceforward, $\mathrm{DAB}$ was rinsed and the slides were counterstaining with Mayer's hematoxylin and cover slipping was performed as the final steps before slides were examined under a light microscope (Olympus CX21, Japan).

The SNpc slides were blindly examined to measure the number of $\mathrm{TH}$ immunopositive cells using an image analysis system "ImageJ 1.45F" (National Institutes of Health, USA). The boundaries of the SNpc were chosen on three consecutive sections corresponding to a representative median plane of the SNpc by examining the size and shape of the different $\mathrm{TH}$-immunoreactive neuronal groups. Cells that were clearly stained for $\mathrm{TH}$ with a visi-

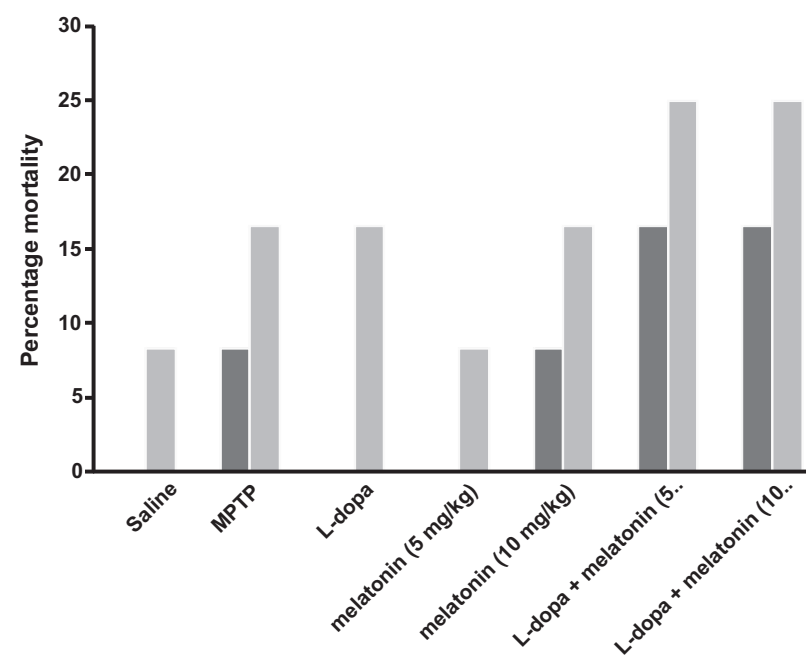

Fig. 2. Mortality percentage in the experimental groups at week 4 and week 8 . Percentage was calculated out of 12 at each time point ble nucleus were counted stereologically in the whole SNpc. In addition, the optical density of caspase-3 immunostaining was determined in the whole SNpc.

\section{Statistical analysis}

Results are expressed as the mean \pm SEM. Measurements were analyzed using two-way analysis of variance, ANOVA, followed by Newman Keuls post-hoc test. Mortality percentage was compared at each time point using $\chi^{2}$ test. All statistical tests were done employing the Statistical Package for Social Sciences, version 17 (SPSS Software, SPSS Inc., Chicago, USA) and the differences were considered significant at $\mathrm{p}<0.05$.

\section{Results}

In the present study, injection of MPTP $(20 \mathrm{mg} / \mathrm{kg} /$ $2 \mathrm{~h} / 4$ doses, ip $)$ in mice produced functional impairment in the motor tests. This was accompanied by biochemical deficits and histopathological changes in the substantia nigra dopaminergic neurons.

\section{Assessment of mortality percentage}

In the present study, the mortality percent recorded in MPTP group was $8.3 \%$ at week 4 and increased to be $16.6 \%$ at week 8 ; these mortality percentages did not differ from those recorded in saline group or the other study groups (Fig. 2).

\section{Assessment of the motor function}

\section{Grid walking test}

In the grid walking test, statistical analysis using ANOVA indicated a difference in the percentage of foot slip errors after treatment with the selected regimens at the two time points, at week $4[\mathrm{~F}(6,28)=$ $7.86, \mathrm{p} \leq 0.01]$ and week $8[\mathrm{~F}(6,28)=12.48, \mathrm{p} \leq$ 0.01]. Post-hoc analysis revealed that MPTP group showed high percentage of foot slip errors compared to saline group; treatment with L-dopa decreased the percentage of errors as compared to MPTP group. However, treatment with melatonin ( 5 and $10 \mathrm{mg} / \mathrm{kg}$ ) improved the walking behavior in the grid test and de- 
creased the percentage of foot slip errors in comparison with MPTP group. Importantly, at week 8, mice treated with melatonin ( 5 and $10 \mathrm{mg} / \mathrm{kg}$ ) in combination with L-dopa showed lower errors compared to those treated with L-dopa alone ( $\mathrm{p} \leq 0.05$, Fig. 3A).
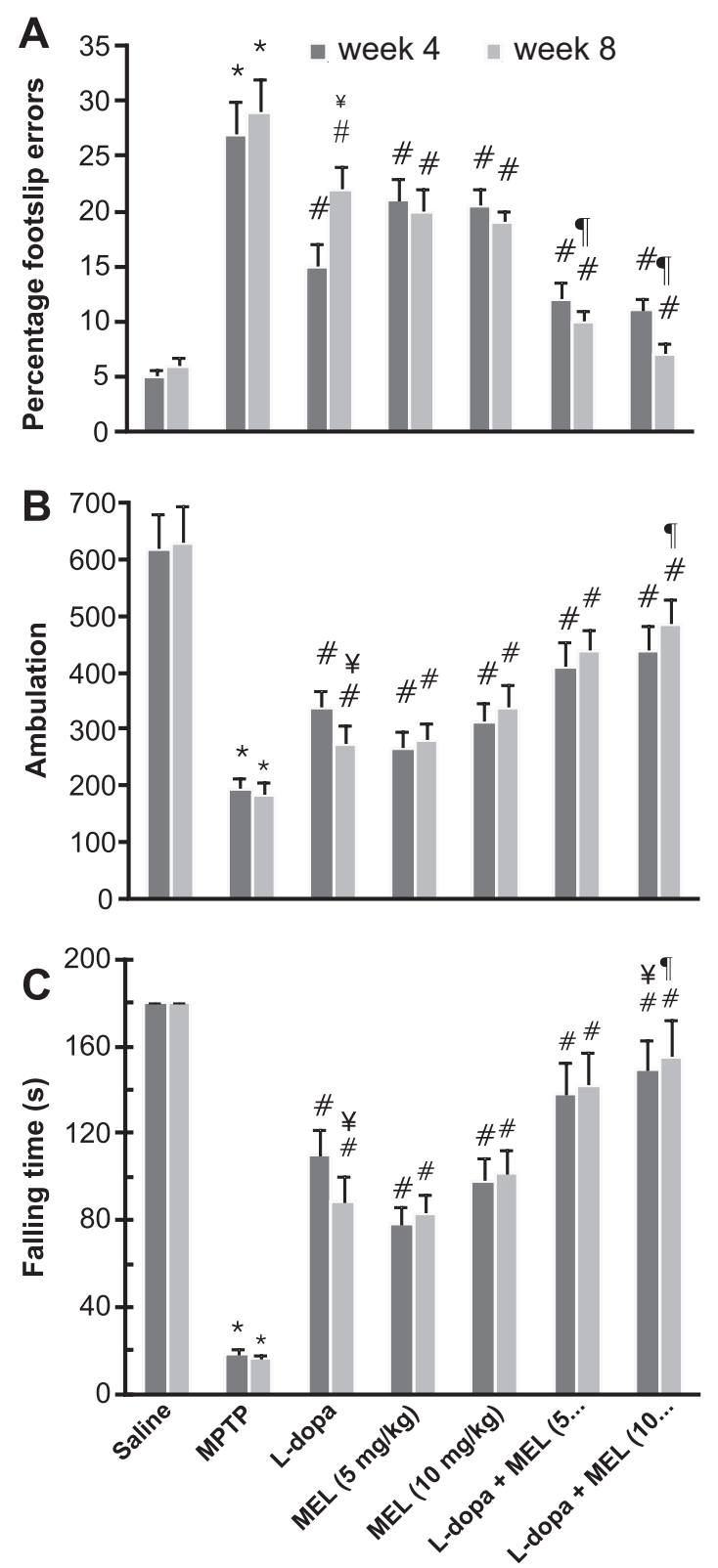

Fig. 3. (A) The percentage of foot slips errors for the experimental groups in the grid walking test. Quantification reveals that MPTP group showed significantly more foot slips errors than saline group throughout the testing period (2 min). (B) The ambulation frequency for the mice in the open field test. (C) The falling time for the mice in the rotarod test. Data are the mean \pm SEM and analyzed using twoway ANOVA and Newman Keuls post-hoc test. * $p \leq 0.05$ compared to saline group at the same time point, ${ }^{\#} \mathrm{p} \leq 0.05$ compared to MPTP group at the same time point, ${ }^{¥} p \leq 0.05$ compared to L-dopa group at week $4,{ }^{\uparrow} p \leq 0.05$ compared to L-dopa group at week 8

\section{Open-field test}

Statistical analysis using ANOVA indicated a difference $[\mathrm{F}(6,28)=3.16, \mathrm{p} \leq 0.01$ at week 4$]$ and $[\mathrm{F}(6,28)=$ $8.26, \mathrm{p} \leq 0.01$ at week 8$]$ in ambulation in the open field test after treatment with the selected drugs. Post-hoc analysis revealed that ambulation in the MPTP group was significantly lower than that recorded in the saline group. The ambulation recorded in L-dopa group at week 8 was significantly lower than that recorded at week 4; indicating a decrease in response to L-dopa. At week 8 , combination of the high dose of melatonin (10 $\mathrm{mg} / \mathrm{kg}$ ) with L-dopa provided higher ambulation compared to the per se effect of L-dopa (Fig. 3B).

\section{Rotarod test}

Statistical analysis using ANOVA indicated a difference in the falling time in the rotarod test after treatment with the selected drugs at the two time points, at week $4[\mathrm{~F}(6,28)=5.19, \mathrm{p} \leq 0.01]$ and week 8 $[\mathrm{F}(6,28)=13.21, \mathrm{p} \leq 0.001]$. Post-hoc analysis indicated that the falling time in the rotarod test was found to be shorter in MPTP group as compared to saline group. L-dopa-treated group showed shorter falling time at week 8 compared to that recorded at week 4. All the treatment regimens improved the falling time as compared to MPTP group ( $\mathrm{p} \leq 0.05$, Fig. $3 \mathrm{C}$ ). The combination of L-dopa and melatonin $(10 \mathrm{mg} / \mathrm{kg})$ showed longer falling time in comparison to L-dopa alone at the end of week 4 as well as week 8 .

\section{Biochemical measurements}

\section{Dopamine level}

Statistical analysis using ANOVA indicated a difference in the striatal dopamine level among the study groups at week $4[\mathrm{~F}(6,28)=4.56, \mathrm{p} \leq 0.01]$ and week $8[\mathrm{~F}(6,28)=6.24, \mathrm{p} \leq 0.001]$. Post-hoc analysis revealed that MPTP-treated mice showed a significant decreased in striatal dopamine level as compared to the saline-treated mice (Fig. 4). Daily treatment with L-dopa, melatonin (5 and $10 \mathrm{mg} / \mathrm{kg}$ ) or their combination increased the striatal dopamine level in comparison to MPTP group ( $\mathrm{p} \leq 0.05$, Fig. 4 ). In addition, the combination of L-dopa with melatonin $(10 \mathrm{mg} / \mathrm{kg})$ showed greater striatal dopamine level compared to the per se effect of L-dopa at week 4 as well as week 8 . 


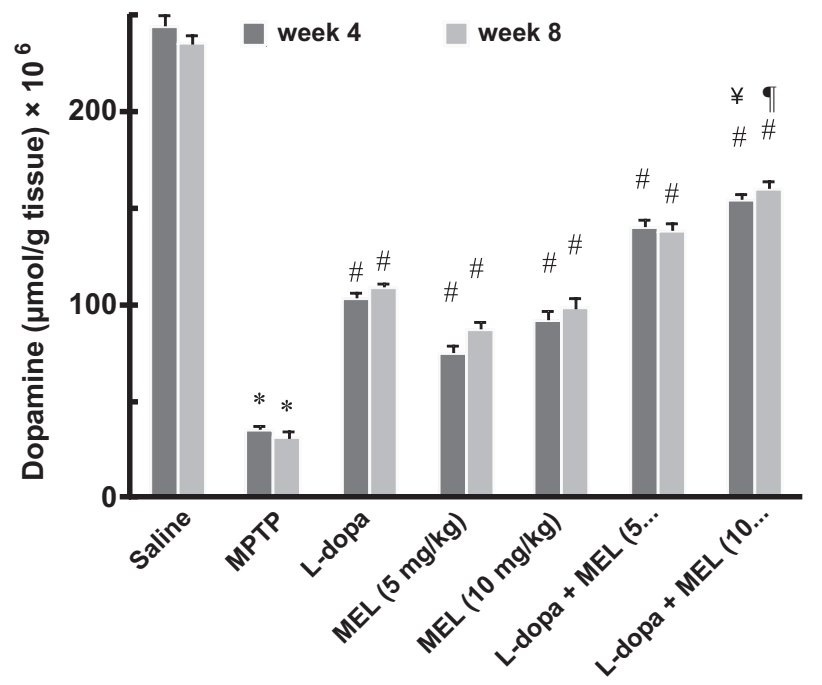

Fig. 4. Striatal dopamine level in the experimental groups. Mice were injected with four doses of MPTP (20 mg/kg, ip) to induce experimental parkinsonism. Results are expressed as the mean \pm SEM and analyzed using two-way ANOVA and Newman Keuls post-hoc test. Units in $\mu \mathrm{M} / \mathrm{g}$ tissue $\times 10^{-6}$ means units are in $\mathrm{pM} / \mathrm{g}_{\text {tissue. }}{ }^{*} \mathrm{p} \leq 0.05 \mathrm{com}$ pared to saline group at the same time point, ${ }^{\#} p \leq 0.05$ compared to MPTP group at the same time point, ${ }^{*} p \leq 0.05$ compared to L-dopa group at week $4,{ }^{\uparrow} p \leq 0.05$ compared to $L$-dopa group at week 8

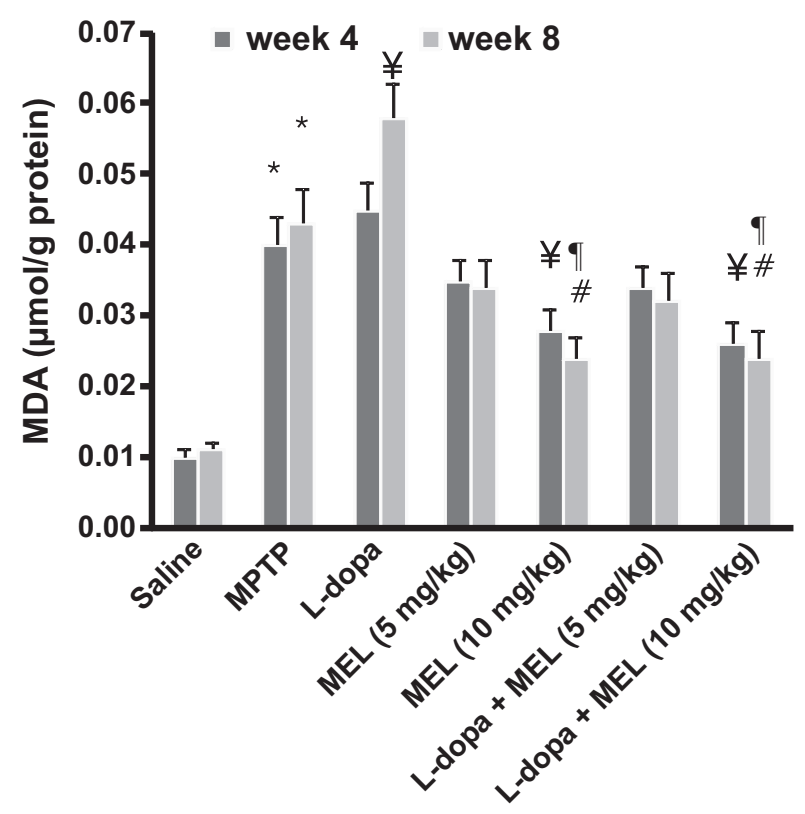

Fig. 5. Malondialdehyde (MDA) in the brains of the experimental groups. MPTP group (20 mg/kg/2 h/4 doses, ip) showed higher levels of MDA as compared to saline group. Results are expressed as the mean \pm SEM and analyzed using two-way ANOVA and Newman Keuls post-hoc test. * $p \leq 0.05$ compared to saline group at the same time point, ${ }^{\#} \mathrm{p} \leq 0.05$ compared to MPTP group at the same time point, ${ }^{\sharp} p \leq 0.05$ compared to $L$-dopa group at week $4,{ }^{n} p \leq 0.05 \mathrm{com}$ pared to L-dopa group at week 8

\section{Lipid peroxides}

Statistical analysis using ANOVA indicated a difference in MDA level after treatment with the selected drugs at week $4[\mathrm{~F}(6,28)=6.21, \mathrm{p} \leq 0.01]$ and week $8[\mathrm{~F}(6,28)=7.21, \mathrm{p} \leq 0.01]$. Post-hoc analysis demonstrated that MPTP group showed higher concentration of tissue MDA compared to saline group at week 4 as well as week 8 ( $\mathrm{p} \leq 0.05$, Fig. 5). At week 8 , L-dopa group showed higher MDA level in comparison to MPTP group. Further, melatonin $(10 \mathrm{mg} / \mathrm{kg})$ induced a significant reduction in the elevated MDA level compared to both, MPTP group and L-dopa group. The combination of L-dopa with melatonin $(10 \mathrm{mg} / \mathrm{kg})$ reduced tissue MDA in comparison to MPTP group as well as L-dopa group (Fig. 5).

\section{Glutathione concentration}

Statistical analysis using ANOVA revealed a difference in tissue GSH level among the study groups at week $4[\mathrm{~F}(6,28)=5.19, \mathrm{p} \leq 0.01]$ and week 8 $[\mathrm{F}(6,28)=13.21, \mathrm{p} \leq 0.001]$. MPTP administration induced a significant decrease in the tissue GSH content as compared to the saline group at week 4 and week 8. L-dopa group did not show a difference in GSH level in comparison to MPTP group. Both doses of melatonin $(5$ or $10 \mathrm{mg} / \mathrm{kg})$ in combination with Ldopa, induced significant increases in tissue GSH in comparison to MPTP group as well as L-dopa group at week 4 as well as week 8 ( $\leq \leq 0.05$, Fig. 6$)$.

\section{GP-x, SOD and CAT}

Furthermore, analysis of variance highlighted a difference in the tissue enzyme activities among the study groups at the two time points. At week $4, \mathrm{~F}(6,28)=$ $4.11(\mathrm{p} \leq 0.05)$ for GSH-Px, F $(6,28)=4.11(\mathrm{p} \leq$ $0.05)$ for SOD and $\mathrm{F}(6,28)=4.11,(\mathrm{p} \leq 0.05)$ for CAT. Whereas, at week $8, \mathrm{~F}(6,28)=6.43(\mathrm{p} \leq 0.01)$ for GSH-Px, F $(6,28)=4.21(\mathrm{p} \leq 0.01)$ for SOD and $\mathrm{F}(6,28)=5.16(\mathrm{p} \leq 0.01)$ for CAT. Post-hoc analysis indicated that GP-x, SOD and CAT activities were lower in MPTP-treated mice compared to salinetreated mice at week 4 and 8 . L-dopa group did not differ significantly from MPTP group at the two time points. Monotherapy with melatonin or combination with L-dopa induced a significant increase in the antioxidant enzymes activities compared to MPTP group or single L-dopa therapy (Fig. 7). 


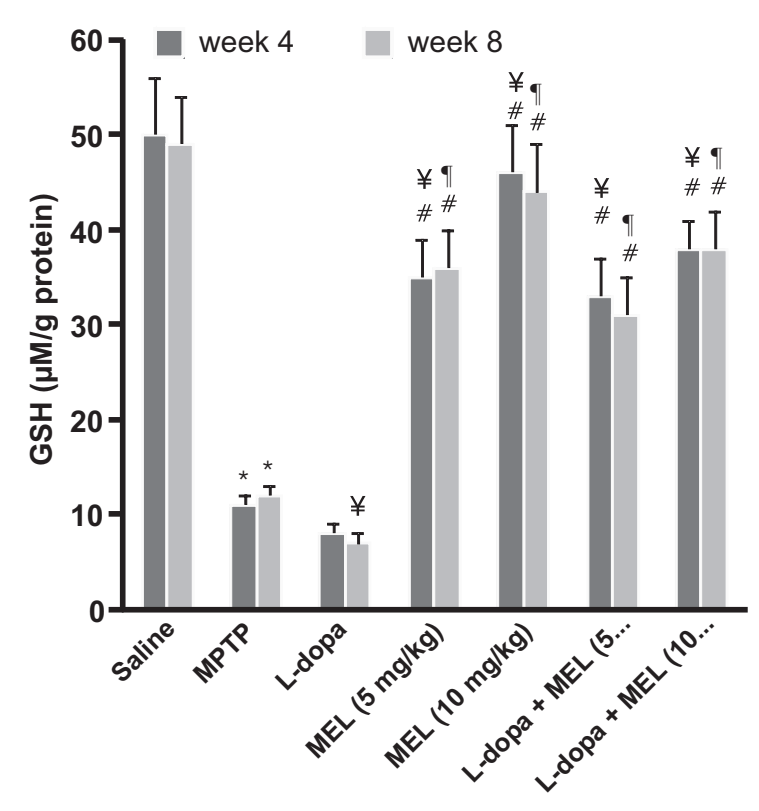

Fig. 6. Reduced glutathione (GSH) in the brains of the experimental groups. Results are expressed as the mean \pm SEM and analyzed using two-way ANOVA and Newman Keuls post-hoc test. ${ }^{*} p \leq 0.05$ compared to saline group at the same time point, ${ }^{*} p \leq 0.05 \mathrm{com}$ pared to MPTP group at the same time point, ${ }^{*} p \leq 0.05$ compared to L-dopa group at week $4, \uparrow_{\mathrm{p}} \leq 0.05$ compared to L-dopa group at week 8

\section{Immunohistochemical evaluation for $\mathrm{TH}$ and caspase-3}

Immunohistochemical staining for $\mathrm{TH}$ positive neurons demonstrated that saline-treated mice showed high number of $\mathrm{TH}$ positive neurons. On the other hand, MPTP-treated mice showed a marked decrease in TH positive neurons (Fig. 8A). At week 4, single treatment with melatonin $(10 \mathrm{mg} / \mathrm{kg})$, or its combination with L-dopa, increased the number of $\mathrm{TH}$ positive neurons compared to MPTP group (Fig. 8B). At week 8, all the treatment regimens improved $\mathrm{TH}$ immunostaining compared to MPTP group as well as L-dopa group (Fig. 8B).

Regarding caspase-3 immunostaining, saline-treated mice showed low optical density for caspase-3, whereas, MPTP group showed higher optical density for caspase-3 (Fig. 9A). L-dopa group did not differ significantly from MPTP group. All of the other treatment regimens ameliorated caspase- 3 immunostaining in the SNpc (Fig. 9B).
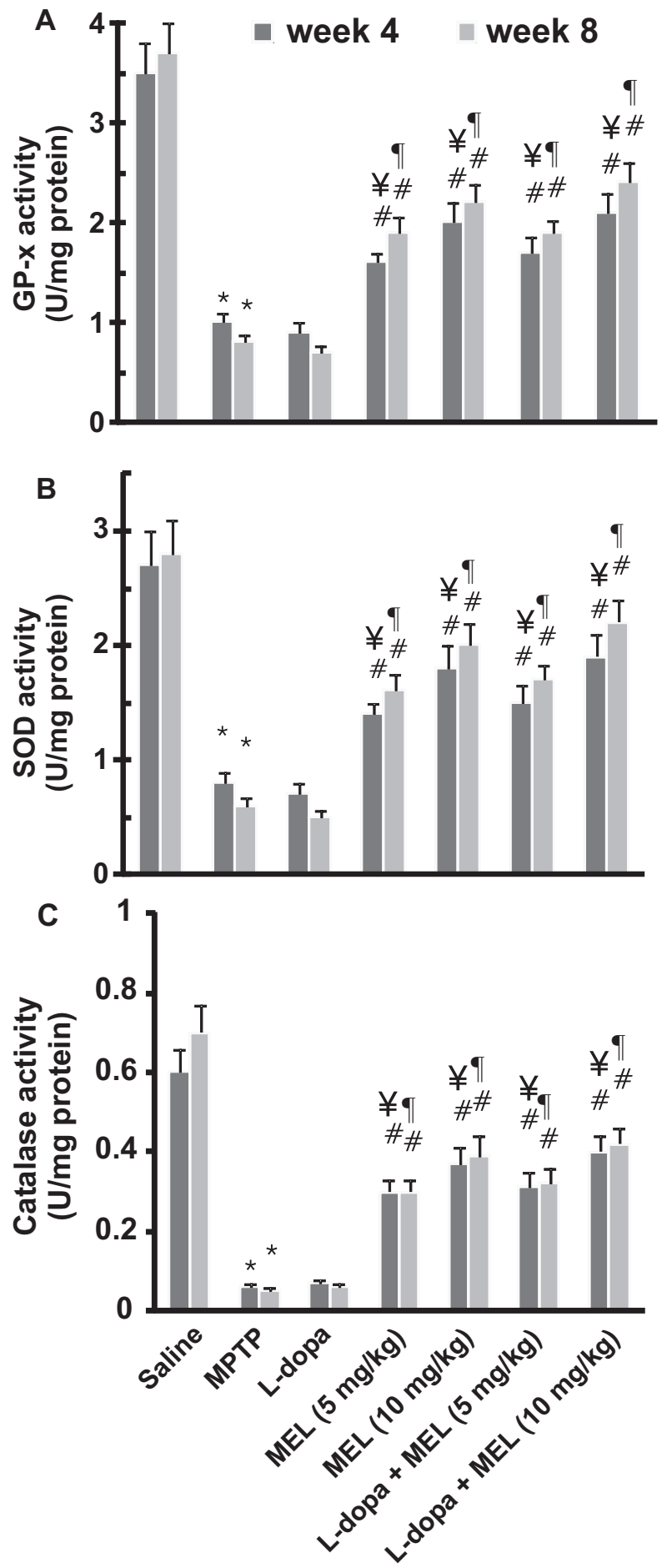

Fig. 7. Activities of the antioxidant enzymes glutathione peroxidase $(\mathrm{GP}-\mathrm{x})(\mathbf{A})$, superoxide dismutase (SOD) $(\mathbf{B})$ and catalase $(\mathbf{C})$ in the brains of the experimental groups. Results are expressed as the mean \pm SEM and analyzed using two-way ANOVA and Newman Keuls post-hoc test. * $p \leq 0.05$ compared to saline group at the same time point, ${ }^{\#} \mathrm{p} \leq 0.05$ compared to MPTP group at the same time point, ${ }^{¥} p \leq 0.05$ compared to $L$-dopa group at week $4,{ }^{\Uparrow} p \leq 0.05 \mathrm{com}$ pared to L-dopa group at week 8 

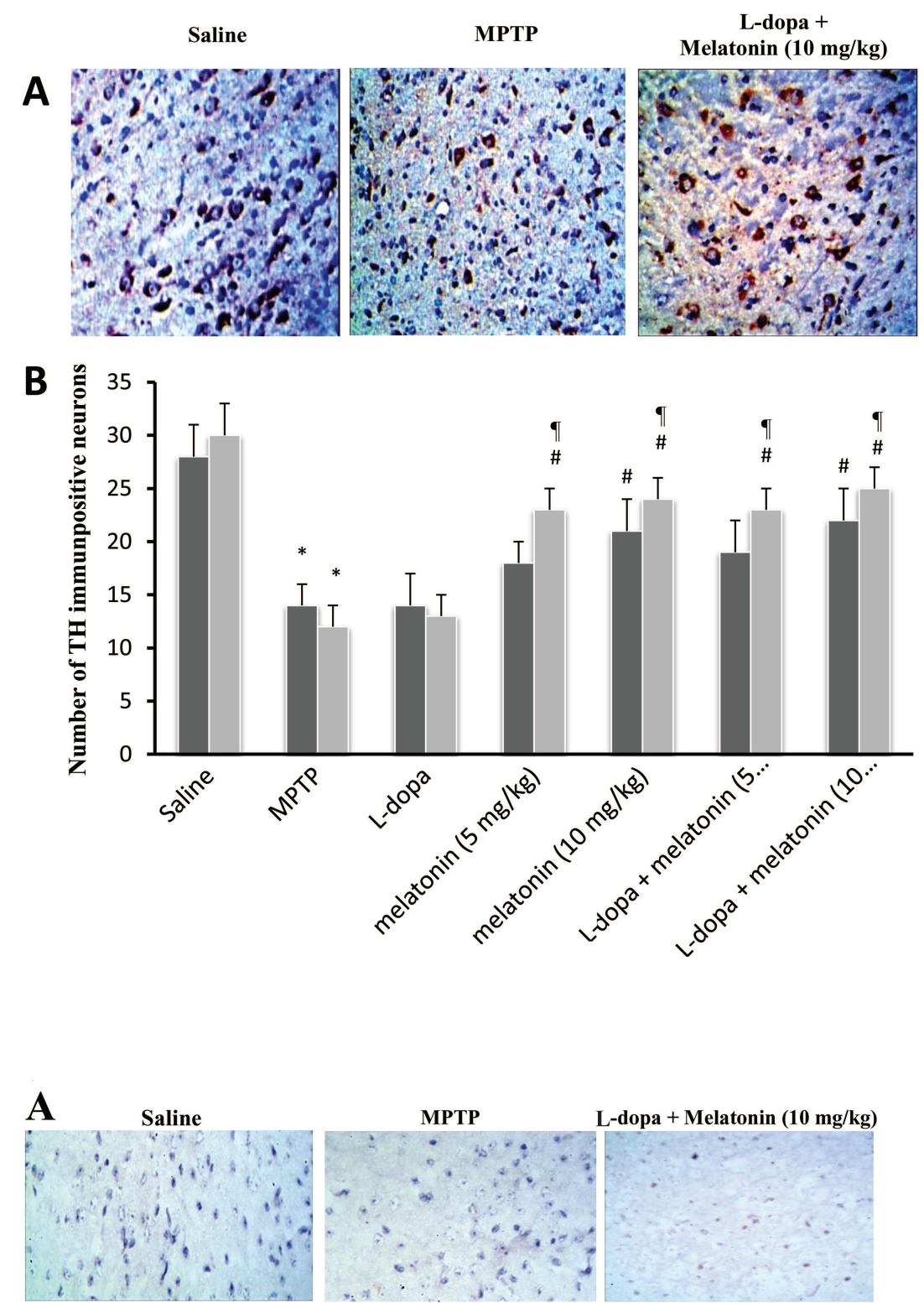

B

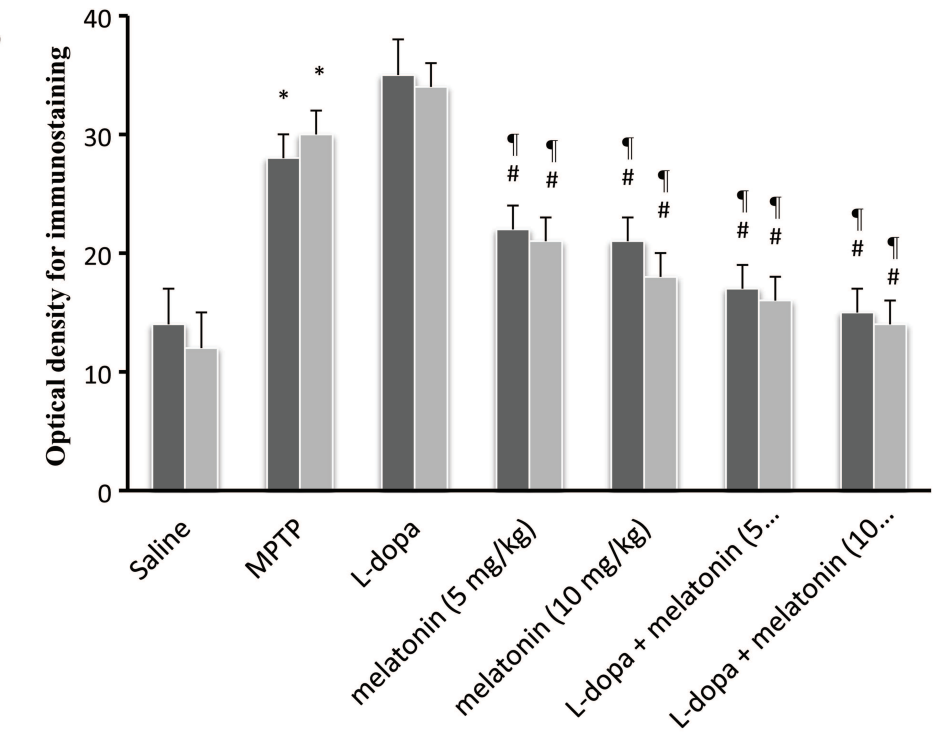

Fig. 8. Immunohistochemical staining for tyrosine hydroxylase (TH) in the substantia nigra neurons from the experimental groups at the end of week 8. (A) Photomicrographs from sections in the SNpc of some of the experimental group (scale bar: $86.57 \mu \mathrm{m}$ ) [DAB \& Mayer's hematoxylin counter stain]. (B) Number of immunpositive neurons in the experimental groups. Results are expressed as the mean \pm SEM and analyzed using two-way ANOVA and Newman Keuls post-hoc test. * $\mathrm{p} \leq$ 0.05 compared to saline group at the same time point, ${ }^{\#} p \leq 0.05$ compared to MPTP group at the same time point, * $p \leq 0.05$ compared to L-dopa group at week 4, १ $p \leq 0.05$ compared to L-dopa group at week 8
Fig. 9. Immunohistochemical staining for caspase-3 in the substantia nigra neurons from the experimental groups at the end of week 8. (A) Photomicrographs from sections in the SNpc of saline group showing low immunopositive reactions. MPTP group showed higher immunopositive reaction. Mice treated with L-dopa + melatonin (10 mg/kg) showed lower immunostaining for caspase-3 (scale bar: 213 um) [DAB \& Mayer's hematoxylin counter stain]. (B) Optical density for the immune reaction in the substantia nigra pars compacta in the experimental groups. Results are expressed as the mean \pm SEM and analyzed using two-way ANOVA and Newman Keuls post-hoc test. * $p \leq 0.05$ compared to saline group at the same time point, ${ }^{\#} \mathrm{p}$ $\leq 0.05$ compared to MPTP group at the same time point, ${ }^{¥} p \leq 0.05$ compared to L-dopa group at week $4,{ }^{n} p \leq 0.05$ compared to L-dopa group at week 8 


\section{Discussion}

ROS, like the superoxide radical and $\mathrm{H}_{2} \mathrm{O}_{2}$, are the results of aerobic metabolism in the brain as this organ, more than any other, produces a significant amount of ROS. In neurodegenerative disorders, like PD, the antioxidant defense systems dwindle and the oxidative load increases [41]. Dopaminergic neurons exert greater oxidative stress than other neurons owing to the production of $\mathrm{H}_{2} \mathrm{O}_{2}$ during monoamine oxidase-driven dopamine metabolism [24].

In the current study, MPTP-treated mice exhibited impaired motor activity accompanied by a marked decrease in striatal dopamine level. The current results demonstrated that MDA was higher in the brains of MPTP-treated mice compared to saline-treated mice. In accordance, complex I inhibition was suggested to induce cell death in primary dopaminergic culture by increasing ROS production and inhibiting mitochondrial respiration [40].

MPTP group demonstrated a decrease in striatal GSH as well as antioxidant enzyme activities. Although glutathione is not the only antioxidant molecule reported to be altered in PD, the magnitude of glutathione depletion appears to parallel the severity of the disease and is the earliest known indicator of nigral degeneration. It was reportedly preceding detectable losses in both mitochondrial complex I activity and striatal dopamine content [21]. Oxidative stress from MPTP-induced ROS could easily overload the intrinsic anti-oxidative system resulting in cell death. These findings are compatible with those reported that oxidative stress could be involved in the pathogenic mechanisms of PD [45]. Consistently, low density of GSH positive cells was found surrounding the dopaminergic neurons [12], which along with GSH-Px form the primary defense system of dopaminergic neurons against ROS. The present study demonstrated diminished GSH-Px, SOD and CAT activity in MPTP-treated mice compared to salinetreated mice. Similarly, the SNpc of PD brains has a reduced level of the antioxidant enzymes such as CAT, SOD and GSH-Px [49] and antioxidant molecules such as GSH [50], suggesting the presence of a sustained burden of oxidative stress that overwhelmed the antioxidant capacity.

In the current study, L-dopa treated group exhibited higher MDA level compared to MPTP group at week 8 only. However, there was a non significant decrease in GSH as well as the activities of the antioxidant en- zymes. Dopamine within the neuron is metabolized by MAO-A to dihydroxyphenylacetic acid (DOPAC), $\mathrm{H}_{2} \mathrm{O}_{2}$ is kicked out in the process, and oxygen and water are consumed [15]. Dopamine also undergoes autooxidation to dopamine-quinone and generates $\mathrm{H}_{2} \mathrm{O}_{2}$ in a reaction that involves a nucleophilic addition with protein sulfhydryl groups [17] and the reduction of GSH, the major cellular buffer that metabolizes $\mathrm{H}_{2} \mathrm{O}_{2}$ and prevents oxidative stress in the neuron [51]. If there is decreased GSH, then there is no buffer to the $\mathrm{H}_{2} \mathrm{O}_{2}$ that is present in nigral tissues. In addition, it has been suggested that in addition to generation of $\mathrm{H}_{2} \mathrm{O}_{2}$ and quinone formation, L-dopaand dopamine-induced cell death were reported to be attributed to the induction of apoptosis, as evidenced by increases in caspase-3 activity [38].

Daily treatment with L-dopa for seven weeks showed a gradual decrease in the therapeutic response that became of significance at week 8 in some of the motor parameters when compared to the corresponding values at week 4 . Several potential mechanisms may explain these results; oxidative stress in the substantia nigra could result from overactivity of surviving dopamine neurons with increased hydrogen peroxide production. These changes could promote the formation of ROS and induce oxidative damage. The addition of L-dopa under these conditions could add to the pro-oxidant environment in the substantia nigra. Both L-dopa and dopamine undergo oxidative metabolism and can thereby generate cytotoxic free radicals and other oxidizing species. The quinone products of L-dopa autooxidation can bind to and deplete GSH levels, thereby further reducing antioxidant defenses available to dopamine neurons [33]. Treatment with L-dopa in the current study did not appear at week 4 but was observed only at week 8 ; this may be related to the gradual decline (even non significant) in GSH and the antioxidant enzyme activities.

It has been reported that L-dopa therapy increased the concentration of 2,3-dihydroxybenzoate in platelets of PD patients [29], other studies have described no correlation between the dose of L-dopa and basal plasma oxidative status measured as serum MDA [53] or blood hydroxyl radicals and plasma [5]. L-dopa is used in PD therapy, since it can be converted enzymatically to dopamine, restoring its levels. Autoxidation, increasing, even more, the oxidative stress situation at nigrostriatal sites and L-dopa-treated patients will be at greater risk [6]. With regard to antioxidant treatment, L-dopa administration in rats induces formation of 
L-dopa-semiquinone, which can act as oxidant, decreasing dopamine and ascorbic acid levels [46].

In the current study, monotherapy with melatonin or combination therapy with L-dopa ameliorated MPTP-induced parkinsonism in mice. The combination of melatonin with L-dopa further enhanced the motor response to L-dopa and prevented the timedependent decline in the response to L-dopa. Further, melatonin - with or without L-dopa - improved the oxidative status in MPTP-parkinsonian mice. Thus, functional assessment came on line with biochemical and histopathologic assessment. Melatonin, as an electron-rich molecule, is able to interact with free radicals through consecutive reactions giving rise to many stable compounds that can be excreted by urine [28]. In fact, the melatonin antioxidant mechanism implied a free radical scavenger's cascade, since secondary, and even tertiary, metabolites are also efficient free radicals scavengers [45]. The formation of such metabolites from melatonin implies that, unlike classic antioxidants, melatonin does not produce prooxidant reactions [1] and its metabolites were more potent than melatonin itself [3].

The metabolites of melatonin are able to reduce 8hydroxy-2-deoxyguanosine [8] and lipid peroxidation. Furthermore, it can interact with $\cdot \mathrm{OH}$, the most reactive free radical. This is supported experimentally by numerous data that show that melatonin is able to protect lipids in the cellular membranes, proteins in the cytosol and DNA in the nucleus from free radical damage [42].

In the current study, melatonin improved the antioxidant enzymes activities in MPTP-parkinsonian mice. One of the main characteristic of melatonin is that its antioxidant function is developed also through the antioxidant enzymes activation. Thus, the indoleamine is an ideal molecule to fight against oxidative stress. Many are the works which show that melatonin treatment is able to increase the activity and/or the expression of the main antioxidant enzymes, such as SOD, CAT, GSH-Px and glutathione reductase. The studies developed with regard to antioxidant enzyme activation started with the administration of exogenous melatonin to rats, showing an increase in the GSH-Px activity. It has been shown, in rat brain cortex, that melatonin administration increases MnSOD $\mathrm{Cu} / \mathrm{Zn}$ SOD, GSH-Px and CAT mRNA levels [30]. Melatonin treatment immediately post-surgery attenuates dopaminergic denervation in the 6-OHDAlesioned rat striatum when administered at physio- logical concentrations [49]. Melatonin has been reported to induce antioxidant enzymes such as SOD [26] and GSH-Px activities, to prevent oxidative damage [43] and protect against clomiphene citrateinduced generation of $\mathrm{H}_{2} \mathrm{O}_{2}$ in rat eggs [55]. Lastly, only high doses of melatonin are able to suppressed iron-induced neurodegeneration of the nigrostriatal dopaminergic system when administered locally or after 7 days repetitive systemic injection [25].

In fact, some authors consider that melatonin treatment in PD has little to do to improve the situation, since dopamine autooxidation is a process initiated many years before first symptoms are discovered and an antioxidant therapy has little to do at this level. There are increasing amount of evidences that in both in vivo and in vitro nigrostriatal system, the oxidative damage induced by $\mathrm{MPP}^{+}$can be prevented by the use of a variety of antioxidants which either can suppress the formation of free radicals or activate the antioxidative defense mechanisms, scavenging free radicals [2]. Among them, the radical scavenging and antioxidative activities of melatonin are also reported both in vitro and in vivo [15]. The results of Jin et al. [22] showed that $\mathrm{MPP}^{+}$-induced rises of lipid peroxidation product, MDA decreased following the treatment of melatonin may also support the antioxidative effects of melatonin.

Further, melatonin was reported to protect nigral dopaminergic neurons from MPTP neurotoxicity [22] and against 6-OHDA-induced neurotoxicity in rats [11]. Chetsawang et al. studied the neuroprotective effect of melatonin against the induction of c-Jun phosphorylation by 6-hydroxydopamine on SK-N-SH cells [9]. Their results demonstrate some protective properties of melatonin against neuronal cell degeneration and its action on the inhibition of c-Jun-N terminal kinase signaling cascade. More recently, melatonin was reported to inhibit amphetamine-induced increase in $\alpha$-synuclein and decrease in phosphorylated tyrosine hydroxylase in SK-N-SH cells [23].

\section{Conclusion}

In the present study, daily treatment with L-dopa improved the motor performance of MPTP-parkinsonian mice while worsened the biochemical parameters. Importantly, there was a gradual decrease in the response 
to L-dopa which was accompanied by high brain MDA level; treatment with melatonin improved the motor function of mice. In addition, melatonin - with or without L-dopa - suppressed the production of MDA and increased GSH level in the MPTP-parkinsonian mice. Based on the previous findings, agents that modulate oxidative stress would be promising candidates for neuroprotection in $\mathrm{PD}$ and they can reduce the prooxidant effect of L-dopa.

\section{Conflict of interest:}

The authors report no conflicts of interest.

\section{Acknowledgments}

We would like to acknowledge the generous gift of L-dopa and carbidopa from Global Napi Pharmaceuticals (Cairo, Egypt). This work did not receive any financial support from any organization.

\section{References:}

1. Abudu N, Miller JJ, Attaelmannan M, Levinson SS: Vitamins in human arteriosclerosis with emphasis on vitamin C and vitamin E. Clin Chim Acta, 2004, 339, $11-25$.

2. Acuna-Castroviejo D, Coto-Momtes A, Gaia Monti M, Oritz GG, Reiter RJ: Melatonin is protective against MPTP induced striatal and hippocampal lesions. Life Sci, 1997, 60, 23-29.

3. Acuna-Castroviejo D, Escames G, Leon J, Carazo A, Khaldy H: Mitochondrial regulation by melatonin and its metabolites: Adv Exp Med Biol, 2003, 527, 549-557.

4. Aebi H: Catalase in vitro. Meth Enzymol, 1984, 105, 121-126.

5. Ahlskog JE, Uitti RJ, Low PA, Tyce GM, Nickander KK, Petersen RC, Kokmen E: No evidence for systemic oxidant stress in Parkinson's or Alzheimer's disease. Mov Disord, 1995, 10, 566-573.

6. Basma AN, Morris EJ, Nicklas WJ, Geller HM: L-dopa cytotoxicity to PC12 cells in culture is via its autoxidation. J Neurochem, 1995, 64, 825-832.

7. Buck K, Ferger B: The selective $\alpha_{1}$ adrenoceptor antagonist HEAT reduces L-dopa-induced dyskinesia in a rat model of Parkinson's disease. Synapse, 2010, 64, 117-126.

8. Burkhardt S, Reiter RJ, Tan DX, Hardeland R, Cabrera J, Karbownik M: DNA oxidatively damaged by chromium(III) and $\mathrm{H}_{2} \mathrm{O}_{2}$ is protected by the antioxidants melatonin, $\mathrm{N}_{1}$-acetyl- $\mathrm{N}_{2}$-formyl-5-methoxykynuramine, resveratrol and uric acid. Int J Biochem Cell Biol, 2001, 33, 775-783.

9. Chetsawang B, Govitrapong P, Ebadi M: The neuroprotective effect of melatonin against the induction of c-Jun phosphorylation by 6-hydroxydopamine on SK-N-SH cells. Neurosci Lett, 2004, 371, 205-208.

10. Correa M, Wisniecki A, Betz A, Dobson DR, O’Neill MF, O’Neill MJ, Salamone JD: The adenosine A2A an- tagonist KF17837 reverses the locomotor suppression and tremulous jaw movements induced by haloperidol in rats: possible relevance to parkinsonism. Behav Brain Res, 2004, 148, 47-54.

11. Dabbeni-Sala F, Di Santo S, Franceschini D, Skaper SD, Giusti P: Melatonin protects against 6-OHDA-induced neurotoxicity in rats: a role for mitochondrial complex I activity. FASEB J, 2001, 15, 164-170.

12. Ebadi M, Srinivasan SK, Baxi MD: Oxidative stress and antioxidant therapy in Parkinson's disease. Prog Neurobiol, 1996, 48, 1-19.

13. Ferraro TN, Golden GT, DeMattei M, Hare TA, Fariello RG: Effect of 1-methyl-4-phenyl-1,2,3,6-tetrahydropyridine (MPTP) on levels of glutathione in the extrapyramidal system of the mouse. Neuropharmacology, 1986, 25, 1071-1074.

14. Foley P, Riederer P: Infuence of neurotoxins and oxidative stress on the onset and progression of Parkinson's disease. J Neurol, 2000, 247, Suppl 2, 82-94.

15. Gesi M, Santinami A, Ruffoli R, Conti G, Fornai F: Novel aspects of dopamine oxidative metabolism (confounding outcomes take place of certainties). Pharmacol Toxicol, 2001, 89, 217-224.

16. Giusti P, Lipartiti M, Franchceschini D, Schiavo N, Floreani M, Manev H: Neuroprotection by melatonin from kainate-induced excitotoxicity in rats. FASEB J, 1996, 10, 891-896.

17. Graham DG, Tiffany SM, Bell WR, Jr., Gutknecht WF: Autoxidation versus covalent binding of quinones as the mechanism of toxicity of dopamine, 6-hydroxydopamine, and related compounds toward C1300 neuroblastoma cells in vitro. Mol Pharmacol, 1996, 14, 644-653.

18. Griffith OW: Determination of glutathione and glutathione disulfide using glutathione reductase and 2vinylpyridine. Anal Biochem, 1980, 106, 207-212.

19. Hoyos M, Guerrero JM, Perez-Cano R, Olivan J, Fabiani F, Garcia-Pergañeda A, Osuna C: Serum cholesterol and lipid peroxidation are decreased by melatonin in dietinduced hypercholesterolemic rats. J Pineal Res, 2000, 28, 150-155.

20. Ihara Y, Chuda M, Kuroda S, Hayabara T: Hydroxyl radical and superoxide dismutase in blood of patients with Parkinson's disease: relationship to clinical data. J Neurol Sci, 1999, 170, 90-95.

21. Jenner P: Oxidative mechanisms in nigral cell death in Parkinson's disease. Mov Disord, 1998, 13, 24-34.

22. Jin BK, Shin, Mi Y. Jeong, Mi R. Gwag, Baik HW: Melatonin protects nigral dopaminergic neurons from 1-methyl-4-phenylpyridinium $\left(\mathrm{MPP}^{+}\right)$neurotoxicity in rats. Neurosci Lett, 1998, 245, 61-64.

23. Klongpanichapaka S, Phansuwan-Pujito P, Ebadi M, Govitrapong P: Melatonin inhibits amphetamine-induced increase in $\alpha$-synuclein and decrease in phosphorylated tyrosine hydroxylase in SK-N-SH cells. Neurosci Lett, 2008, 436, 309-313.

24. Kweon GR, Marks JD, Krencik R, Leung EH, Schumacker PT, Hyland K, Kang UJ: Distinct mechanisms of neurodegeneration induced by chronic complex I inhibition in dopaminergic and non-dopaminergic cells. J Biol Chem, 2004, 279, 51783-51792. 
25. Lin AM, Ho LT: Melatonin suppresses iron-induced neurodegeneration in rat brain. Free Radic Biol Med, 2000, 28, 904-911.

26. Liu F, Ng TB: Effect of pineal indoles on activities of the antioxidant defense enzymes superoxide dismutase, catalase, and glutathione reductase, and levels of reduced and oxidized glutathione in rat tissues. Biochem Cell Biol, 2000, 78, 447-453.

27. Lowry OH, Rosenbrough NJ, Farr AL, Randall RJ: Protein measurement with the folin phenol reagent. J Biol Chem, 1951, 193, 265-275.

28. Ma X, Idle JR, Krausz KW, Gonzalez FJ: Metabolism of melatonin by human cytochromes p450. Drug Metab Dispos, 2005, 33, 489-494.

29. Martignoni E, Blandini F, Godi L, Desideri S, Pacchetti C, Mancini F, Nappi G: Peripheral markers of oxidative stress in Parkinson's disease. The role of L-DOPA. Free Radic Biol Med, 1999, 27, 428-437.

30. Mayo JC, Sainz RM, Antolí I, Herrera F, Martin V, Rodriguez C: Melatonin regulation of antioxidant enzyme gene expression. Cell Mol Life Sci, 2002, 59, 1706-1713.

31. Menet V, Prieto M, Privat A, Ribotta GY: Axonal plasticity and functional recovery after spinal cord injury in mice deficient in both glial fibrillary acidic protein and vimentin genes. Proc Natl Acad Sci USA, 2003, 100, 8999-9004.

32. Mosley RL, Benner EJ, Kadiu I, Thomas M, Boska MD, Hasan K, Laurie C, Gendelman HE: Neuroinflammation, oxidative stress and the pathogenesis of Parkinson's disease. Clin Neurosci Res, 2006, 6, 261-281.

33. Mytilineou C, McNaught KS, Shashidharan P, Yabut J, Baptiste RJ, Parnandi A, Olanow CW: Inhibition of proteasome activity sensitizes dopamine neurons to protein alterations and oxidative stress. J Neural Transm, 2004, 111, 1237-1251.

34. Nishikimi M, Roa NA, Yogi K, Olanow CW: Measurement of superoxide dismutase. Biochem Biophys Res Commun, 1972, 46, 849-854.

35. Ohkawa H, Ohishi N, Yagi K: Assay for lipid peroxides in animal tissues by thiobarbituric acid reaction. Anal Biochem, 1979, 95, 351-358.

36. Olanow W, Obeso JA, Stocchi F: Continuous dopaminereceptor treatment of Parkinson's disease: scientific rationale and clinical implications. Lancet Neurol, 2006, 5, 677-687.

37. Paglia DE, Valentine WN: Studies on the quantitative and qualitative characterization of erythrocyte glutathione peroxidase. J Lab Clin Med, 1967, 70, 158-169.

38. Pedrosa R, Soares-da-Silva P: Oxidative and nonoxidative mechanisms of neuronal cell death and apoptosis by L-3,4-dihydroxyphenylalanine (L-DOPA) and dopamine. Br J Pharmacol, 2002, 137, 1305-1313.

39. Przedborski S, Jackson-Lewis V, Naini AB, Jakowec M, Petzinger G, Miller R, Akram M: The parkinsonian toxin 1-methyl-4-phenyl-1,2,3,6-tetrahydropyridine (MPTP): a technical review of its utility and safety. J Neurochem, 2001, 76, 1265-1274.

40. Radad K, Rausch WD, Gille G: Rotenone induces cell death in primary dopaminergic culture by increasing ROS production and inhibiting mitochondrial respiration. Neurochem Int, 2006, 49, 379-386.
41. Reiter RJ: Oxidative processes and antioxidative defense mechanisms in the aging brain. FASEB J, 1995, 9, 526-533.

42. Reiter RJ, Tan DX, Gitto E, Sainz RM, Mayo JC, Leon J, Manchester LC et al.: Pharmacological utility of melatonin in reducing oxidative cellular and molecular damage. Pol J Pharmacol, 2004, 56, 159-170.

43. Reiter RJ, Tan DX, Manchester LC, Paredes SD, Mayo JC, Sainz RM: Melatonin and reproduction revisited. Biol Reprod, 2009, 81, 445-456.

44. Ren JP, Zhao YW, Sun XJ: Toxic influence of chronic oral administration of paraquat on nigrostriatal dopaminergic neurons in C57BL/6 mice. Chin Med J, 2009, 122, 2366-2371.

45. Ressmeyer AR, Mayo JC, Zelosko V, Sáinz RM, Tan DX, Poeggler B, Antolin I et al.: Antioxidant properties of the melatonin metabolite $\mathrm{N}^{1}$-acetyl-5-methoxykynuramine (AMK): scavenging of free radicals and prevention of protein destruction. Redox Rep, 2003, 8, 205-213.

46. Rocchitta G, Migheli R, Esposito G, Marchetti B, Desole MS, Miele E, Serra PA: Endogenous melatonin protects L-DOPA from autoxidation in the striatal extracellular compartment of the freely moving rat: potential implication for long-term L-DOPA therapy in Parkinson's disease. J Pineal Res, 2006, 40, 204-213.

47. Rotman A, Daly JW, Creveling CR, Breakefield XO: Uptake and binding of dopamine and 6-hydroxydopamine in murine neuroblastoma and fibroblast cells. Biochem Pharmacol, 1976, 25, 383-388.

48. Schwenkgrub J, Joniec-Maciejak I, Sznejder-Pachołek A, Wawer A, Ciesielska A, Bankiewicz K, Członkowska A, Członkowski A: Effect of human interleukin-10 on the expression of nitric oxide synthases in the MPTPbased model of Parkinson's disease. Pharmacol Rep, 2013, 65, 44-49.

49. Sharma R, McMillan CR, Tenn CC, Niles LP: Physiological neuroprotection by melatonin in a 6hydroxydopamine model of Parkinson's disease. Brain Res, 2006, 1068, 230-236.

50. Sian J, Dexter DT, Lees AJ, Daniel S, Agid Y, JavoyAgid F, Jenner P, Marsden CD: Alterations in glutathione levels in Parkinson's disease and other neurodegenerative disorders affecting basal ganglia. Ann Neurol, 1994, 36, 348-355.

51. Sian J, Dexter DT, Lees AJ, Daniel S, Jenner P, Marsden CD: Glutathione-related enzymes in brain in Parkinson's disease. Ann Neurol, 1994, 36, 356-361.

52. Srinivasan V, Pandi-Perumal SR, Maestroni GJ, Esquifino AI, Hardeland R, Cardinali DP: Role of melatonin in neurodegenerative diseases. Neurotox Res, 2005, 7 , 293-318.

53. Tietze F: Enzymic method for quantitative determination of nanogram amounts of total and oxidized glutathione: applications to mammalian blood and other tissues. Anal Biochem, 1969, 27, 502-522.

54. Tomás-Zapico C, Coto-Montes A: Melatonin as antioxidant under pathological processes. Recent Patents Endocr Metab Immune Drug Discov, 2007, 1, 63-82.

55. Tripath A, PremKumar KV, Pandey AN, Khatun S, Mishra SK, Shrivastav TG, Chaube SK: Melatonin protects against clomiphene citrate-induced generation of 
hydrogen peroxide and morphological apoptotic changes in rat eggs. Eur J Pharmacol, 2011, 667, 419-424.

56. Walkinshaw G, Waters CM: Induction of apoptosis in catecholaminergic PC12 cells by L-DOPA. Implications for the treatment of Parkinson's disease. J Clin Invest, 1995, 95, 2458-2464.

57. Zaitone SA, Abo-Elmatty DM, Shaalan AA: Acetyl-Lcarnitine and $\alpha$-lipoic acid affect rotenone-induced dam- age in nigral dopaminergic neurons of rat brain, implication for Parkinson's disease therapy. Pharmacol Biochem Behav, 2012, 100, 347-360.

Received: January 20, 2012; in the revised form: April 26, 2013; accepted: May 22, 2013. 